\title{
Substituição da farinha de peixe em dietas para camarões marinhos cultivados em sistema bioflocos
}

\author{
Bruno Ricardo Scopel(1), Rodrigo Schveitzer(1), Walter Quadros Seiffert(1), Vinícius Pierri(1), \\ Rafael da Fonseca Arantes ${ }^{(1)}$, Felipe do Nascimento Vieira(1) e Luis Alejandro Vinatea ${ }^{(1)}$
}

\begin{abstract}
(1)Universidade Federal de Santa Catarina, Centro de Ciências Agrárias, Departamento de Aquicultura, Laboratório de Camarões Marinhos, Servidão dos Coroas, s/no, CEP 88062-601 Florianópolis, SC. E-mail: brscopel@hotmail.com, rodrigo@lcm.ufsc.br, seiffert@cca.ufsc.br, viniciuspierri87@gmail.com, arantesr75@yahoo.com.br, vieirafn@Icm.ufsc.br, vinatea@mbox1.ufsc.br
\end{abstract}

\begin{abstract}
Resumo - O objetivo deste trabalho foi avaliar a substituição de dois níveis de inclusão de farinha de peixe por outros ingredientes, nas dietas de Litopenaeus vannamei cultivados em sistema bioflocos. Foram avaliadas dietas sem uso de farinha de peixe (dieta A, 100\% de substituição), com inclusão de 12,5\% de farinha de peixe (dieta B, 40\% de substituição) e direta controle com inclusão de $21 \%$ (dieta C, $0 \%$ de substituição). Nas dietas A e B, o farelo de soja e as farinhas de carne e vísceras foram os principais substitutos proteicos. Foram analisados os índices de desempenho dos camarões e os parâmetros físicos e químicos da água de cultivo. Os camarões alimentados com a dieta B apresentaram maior peso final (11,63 $\pm 1,38 \mathrm{~g})$, em comparação aos

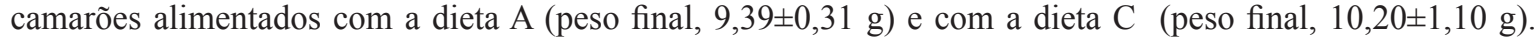
Os demais parâmetros de desempenho como produtividade, conversão alimentar e sobrevivência não apresentaram diferenças entre os tratamentos. A redução de até $40,0 \%$ da farinha de peixe pode ser feita em cultivos superintensivos de L. vannamei com bioflocos, sem interferir em seu desempenho zootécnico e na qualidade de água do cultivo.
\end{abstract}

Termos para indexação: Litopenaeus vannamei, carcinicultura, sistema heterotrófico.

\section{Substitution of fish meal in diets for marine shrimp grown in a biofloc system}

\begin{abstract}
The objective of this work was to evaluate the substitution of two fish meal inclusion levels by other ingredients, in the diets of Litopenaeus vannamei reared in a biofloc system. The following diets were evaluated: without fish meal (diet A, 100\% replacent), with addition of $12.5 \%$ of fish meal (diet B, $40 \%$ replacent), and a control diet with addition of $21 \%$ (diet $\mathrm{C}, 0 \%$ replacent). In diets $\mathrm{A}$ and $\mathrm{B}$, soybean meal and meat and viscera meals were the main protein replacement. The performance indexes of shrimps and the physical and chemical parameters of water were analyzed. Shrimp fed diet B had higher final weight $(11.63 \pm 1.38 \mathrm{~g})$, compared to shrimp fed a diet $\mathrm{A}(9.39 \pm 0.31 \mathrm{~g}$ final weight) or $\mathrm{C}(10.20 \pm 1.10 \mathrm{~g}$ final weight). The other parameters of performance such as yield, feed conversion and survival did not differ between treatments. The reduction of fish meal by $40.0 \%$ can be done in a L vannamei superintensive biofloc system without interfering on their growth performance or on the water quality of the culture.
\end{abstract}

Index terms: Litopenaeus vannamei, shrimp culture, heterotrophic system.

\section{Introdução}

Acarcinicultura é o setor da aquicultura que apresenta os maiores valores de rentabilidade quanto à produção e, assim, seu crescimento acelerado ao redor do mundo, nas últimas décadas, foi inevitável. No entanto, isto causou problemas sanitários e ambientais, com impactos diretos na produção, em razão de doenças graves, que colocaram diversos entraves para o desenvolvimento do cultivo de camarões (Burford, et al., 2004; Food and Agriculture Organization of the United Nations, 2009).

Para solucionar os problemas do setor, diferentes sistemas de produção vêm sendo pesquisados e desenvolvidos ao redor do mundo, para criar alternativas aos produtores e possibilitar a continuidade de seus empreendimentos. Entre essas alternativas está a tecnologia de bioflocos ou biofloc technology (BFT), apontada como uma das mais adequadas e promissoras para o desenvolvimento sustentável da atividade

Pesq. agropec. bras., Brasília, v.46, n.8, p.928-934, ago. 2011 
(Avnimelech, 2009). Esse método de cultivo apresenta diversas vantagens ambientais como baixo ou zero descarte de água, tratamento e reaproveitamento do efluente (Boyd \& Clay, 2002; Otoshi et al., 2009), com grande aproveitamento da biota natural presente na coluna de água como alimento (Chamberlain et al., 2001; Burford et al., 2004), o que possibilita a utilização de diferentes ingredientes proteicos nas dietas, em substituição à farinha de peixe (Kunh et al., 2009; Ray et al., 2010). Quanto ao meio ambiente, há uma atenção especial para a redução da farinha de peixe, uma vez que é produzida principalmente a partir da pesca de pequenos peixes pelágicos, como a sardinha e as anchovetas do Norte do Chile e do Peru. A farinha de peixe é um recurso limitado e finito, e sua utilização excessiva vem sendo severamente criticada por organizações ambientais (Hardy, 2010).

Nas dietas de camarões peneídeos, a farinha de peixe constitui-se como principal ingrediente proteico, principalmente por ser rica em aminoácidos essenciais e ácidos graxos insaturados (HUFA n-3), essenciais para o ótimo desenvolvimento dos camarões; porém, a farinha de peixe é um ingrediente caro e escasso (Tacon \& Metian, 2002; Hardy, 2010).

Com o desenvolvimento da tecnologia de cultivo em bioflocos, com zero ou baixa renovação de água, novos caminhos para a carcinicultura estão sendo trilhados, permitindo mudanças em relação à imagem desta atividade. Neste sistema, grande quantidade de alimento natural composta por flocos microbianos ou bioflocos, como agregados de microalgas, zôoplancton, bactérias, ciliados e flagelados, fornece uma significativa quantidade de nitrogênio à dieta dos camarões e aumenta seu crescimento (Avnimelech, 1999; Chamberlain et al., 2001; Ray et al., 2009). Avnimelech (1999) determinou que a presença de microrganismos, nos tanques de cultivo, aumenta a eficiência da conversão proteica de $20-25,0 \%$ para cerca de $45,0 \%$, pois as bactérias heterotróficas convertem o $\mathrm{N}$ inorgânico presente na água e o disponibilizam na forma de proteína microbiana que é ingerida pelos organismos cultivados. A utilização dos bioflocos permite que espécies de camarões onívoras, como o Litopenaeus vannamei (Boone, 1931), consumam diretamente a biomassa microbiana (Burford et al., 2004; Wasielesky et al., 2006).

Pesquisas têm explorado ouso de plantas e subprodutos animais como alternativa para a substituição da farinha de peixe em cultivos de camarões (Samocha et al., 2004;
Browdy et al., 2006; Amaya et al., 2007; Cruz-Suárez et al., 2007); entretanto, a utilização de farinha de pescado oriunda de rejeitos da pesca, como principal fonte proteica, e sua substituição não foram testados em cultivos de L. vannamei em sistema de bioflocos e alta densidade.

O objetivo deste trabalho foi avaliar a substituição de dois níveis de inclusão de farinha de peixe $(12,5$ e $21,0 \%)$, por outros ingredientes nas dietas de L. vannamei cultivados em sistema bioflocos.

\section{Material e Métodos}

O experimento foi realizado de setembro a dezembro de 2009, no Laboratório de Camarões Marinhos (LCM), da Universidade Federal de Santa Catarina, a $27^{\circ} 34^{\prime} 54^{\prime \prime} \mathrm{N}, 48^{\circ} 26^{\prime} 32^{\prime \prime} \mathrm{W}$, à altitude de $3 \mathrm{~m}$, no Município de Florianópolis, SC. O clima do local é do tipo Cfa, segundo a classificação de Köppen. A água utilizada foi bombeada da praia de Moçambique (salinidade $35 \mathrm{ppt}$ ), filtrada e tratada com hipoclorito de sódio, e preencheu nove tanques de $50 \mathrm{~m}^{2}$ cada um, instalados dentro de duas estufas, os quais foram abastecidos com microalgas Chaetoceros muelleri (Lemmermann, 1898 ) e povoados com pós-larvas de L. vannamei, (pL 20) livres de patógenos específicos ("specific pathogen-free" - SPF), provindas do Laboratório Aquatec, localizado no Município de Canguaretama, RN. O aquecimento da água foi realizado por meio de trocadores de calor elétricos FT-160 (Fromtherm, Florianópolis, SC, Brasil), para manter a água em temperatura ideal $\left(>23^{\circ} \mathrm{C}\right)$ nos dias mais frios.

As pós-larvas foram alimentadas com ração comercial com $40,0 \%$ de proteína bruta, até atingirem o peso de $3,00 \pm 0,5 \mathrm{~g}$; em seguida, deuse início ao experimento com o fornecimento das dietas experimentais. Baixa renovação de água foi utilizada $(0,15 \%$ dia $)$, apenas para a remoção do lodo em excesso. A densidade de povoamento foi de 235 camarões $\mathrm{m}^{-2}$. O controle das concentrações de $\mathrm{N}$ amoniacal $\left(\mathrm{N}-\mathrm{NH}_{4}\right)$ na água foi realizado, tendo-se ajustado a relação entre $\mathrm{C}$ e $\mathrm{N}$ da matéria orgânica que entrava; foi utilizado o melaço de cana em pó, como fonte de C (Avnimelech et al., 1999). A relação C:N foi ajustada próxima a 13:1, durante os dez primeiros dias, para estimular a produção de biomassa bacteriana heterotrófica, a fim de reduzir os compostos nitrogenados tóxicos da água $\left(\mathrm{N}^{-\mathrm{NH}_{4}}\right.$ 
e $\mathrm{N}-\mathrm{NO}_{2}$ ) e mantê-los sempre abaixo de $1 \mathrm{mg} \mathrm{L} \mathrm{L}^{-1}$, para evitar a intoxicação dos camarões (Avnimelech, 1999; Ebeling et al., 2006). Após a estabilização da amônia $\left(\mathrm{N}-\mathrm{NH}_{4}\right)$ e do nitrito $\left(\mathrm{N}-\mathrm{NO}_{2}\right)$, a aplicação de melaço não foi mais necessária. Os camarões foram alimentados durante 76 dias, sem renovação da água.

Nove unidades experimentais receberam aleatoriamente três tratamentos em triplicata (Tabela 1): dieta A, sem farinha de peixe; dieta $\mathrm{B}, 12,5 \%$ de farinha de peixe; dieta C, $21,0 \%$ de farinha de peixe (controle). O controle com $21,0 \%$ de farinha de peixe, na dieta $\mathrm{C}$, foi determinado por ser a quantidade comumente utilizada em dietas comerciais para camarões peneídeos. $\mathrm{Na}$ dieta $\mathrm{B}, 40,0 \%$ da farinha de peixe utilizada no controle, foi sustituida por outos ingredientes. Na dieta A, a substituição foi de $100,0 \%$.

As rações utilizadas foram elaboradas e fabricadas em parceria com a empresa Guabi Nutrição Animal (Campinas, SP, Brasil), de tal forma que todos os aminoácidos essenciais e os fosfolipídeos fossem equilibrados igualmente entre todas as dietas, para atender todas as exigências nutricionais de L. vannamei (Cuzon et al., 2004; Amaya et al., 2007).

Tabela 1. Formulações das três diferentes dietas utilizadas no experimento.

\begin{tabular}{|c|c|c|c|}
\hline \multirow[t]{2}{*}{ Ingrediente } & Dieta A & Dieta B & Dieta $\mathrm{C}$ \\
\hline & \multicolumn{3}{|c|}{------------------- (\%) -------------------- } \\
\hline Farelo de soja $^{(1)}$ & 38,9 & 29,8 & 19,4 \\
\hline Farinha de peixe & 0,0 & 12,5 & 21,0 \\
\hline Carne $43 \%$ & 15,0 & 11,0 & 8,8 \\
\hline Farelo de trigo & 10,0 & 10,0 & 10,0 \\
\hline Levedura de cana ${ }^{(2)}$ & 10,0 & 10,0 & 10,0 \\
\hline Farelo de arroz & 5,0 & 5,0 & 5,0 \\
\hline Melaço líquido & 4,0 & 4,0 & 4,0 \\
\hline Quirera arroz & 3,6 & 6,3 & 8,3 \\
\hline Vísceras & 3,1 & 0,0 & 0,0 \\
\hline Lecitina & 2,6 & 1,3 & 0,0 \\
\hline Penas hidrolizadas & 2,5 & 3,5 & 4,0 \\
\hline Gordura peixe & 1,5 & 2,5 & 1,5 \\
\hline Óleo de atum & 0,0 & 0,0 & 4,0 \\
\hline Fosfato monobicálcico & 1,43 & 1,59 & 1,35 \\
\hline Sal refinado & 0,5 & 0,5 & 0,5 \\
\hline Suplementação vitamínica & 1,90 & 2,01 & 2,15 \\
\hline Total & 100,0 & 100,0 & 100,0 \\
\hline \multicolumn{4}{|c|}{ 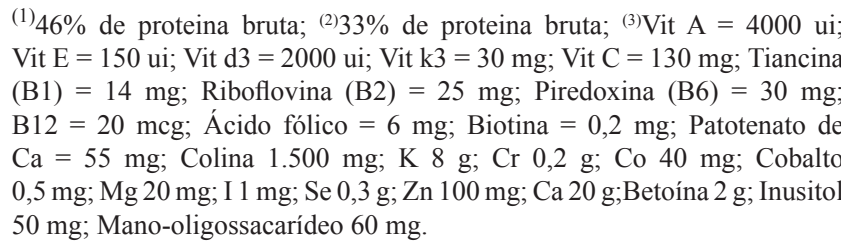 } \\
\hline
\end{tabular}

Nas dietas A e B, o farelo de soja, e as farinhas de carne e de vísceras foram os principais substitutos proteicos. A dieta $\mathrm{C}$ teve a adição de farinha e óleo de peixe, conforme formulado em rações comerciais. Uma quantidade mínima de gordura de peixe foi utilizada como fonte de ácidos graxos altamente insaturados (HUFA n-3) em todas as dietas. A farinha de peixe utilizada nas dietas B e C é de origem nacional, resultante de rejeitos de pesca. As dietas experimentais foram formuladas para serem isoproteicas $(35,0 \% \mathrm{~PB})$, isolipídicas (2,25\% de fosfolipídios) e isoenergéticas, e foram submetidas ao processo de extrusão. O premix vitamínico foi utilizado em todas as dietas, durante todo o experimento.

Os camarões foram alimentados três vezes ao dia (às 8,12 e $18 \mathrm{~h}$ ), por meio de bandejas de alimentação, que proporcionaram o controle de consumo alimentar.

As análises físicas e químicas da água foram realizadas durante todo o cultivo. O oxigênio dissolvido $\left(\mathrm{mg} \mathrm{L} \mathrm{L}^{-1}\right)$ e a temperatura $\left({ }^{\circ} \mathrm{C}\right)$ foram medidos duas vezes ao dia, com oxímetro YSI 55. A salinidade (ppt) foi medida semanalmente por refratrômetro, e o $\mathrm{pH}$ medido semanalmente por $\mathrm{pHmetro}$ digital. Os sólidos sedimentados $\left(\mathrm{mg} \mathrm{L}^{-1}\right)$ foram medidos diariamente com Inhoff método 2540F (Clesceri, 1998); a amônia total $\left(\mathrm{mg} \mathrm{L}^{-1}\right)$ foi medida diariamente conforme Strickland \& Parsons (1972); e o nitrito, o nitrato e o fosfato foram medidos semanalmente $\left(\mathrm{mg} \mathrm{L}^{-1}\right)$, conforme Strickland \& Parsons (1972), assim como a alcalinidade $\left(\mathrm{mg} \mathrm{L}^{-1}\right)$ (Clesceri, 1998).

A taxa de sobrevivência (\%), o ganho de peso semanal (g por semana), a biomassa $(\mathrm{kg})$, a conversão alimentar e a produtividade foram calculados conforme as seguintes expressões: taxa de sobrevivência (\%) = (número final de camarões/número inicial de camarões) $\mathrm{x} 100$; ganho de peso semanal $(\mathrm{g}$ por semana $)=$ ganho em peso/semanas de cultivo; biomassa $(\mathrm{kg})=$ peso úmido médio final $\mathrm{x}$ total de camarões no tanque; conversão alimentar = consumo de ração/ganho em peso; produtividade $\left(\mathrm{kg} \mathrm{m}^{-3}\right)=$ biomassa final/volume total.

Os dados foram analisados quanto à normalidade pelo teste de Kolmogorov-Smirnof e quanto à homogeneidade de variâncias pelo teste de Levene (Sokal \& Rohlf, 1995). Os dados de sobrevivência foram transformados para arc sen $\mathrm{y}^{0,5}$. Os dados de produtividade, conversão alimentar, sobrevivência e ganho de peso semanal foram analisadas por ANOVA 
unifatorial. Diferenças significativas entre as médias dos tratamentos foram avaliadas pelo teste de Tukey HSD (Sokal \& Rohlf, 1995). Todos os dados foram analisados a $5 \%$ de probabilidade.

Todas as variáveis medidas ao longo do tempo, nos parâmetros físicos e químicos, foram testadas pela ANOVA bi-fatorial. Diferenças significativas entre as médias dos tratamentos e semanas de cultivo foram avaliadas pelo teste de Tukey HSD (Sokal \& Rohlf, 1995), a 5\% de probabilidade. Quando detectada a presença de interação significativa entre o tipo de ração e o tempo de cultivo, o teste Tukey HSD foi utilizado para determinar as relações entre os fatores, a $5 \%$ de probabilidade.

\section{Resultados e Discussão}

O experimento foi realizado em 76 dias, para simular todo o ciclo de cultivo. O sistema mostrou-se muito estável, como já relatado por Avnimelech (2009), com poucas flutuações, principalmente de oxigênio, temperatura, $\mathrm{pH}$ e amônia.

Os ganhos de peso semanal e peso final dos animais apresentaram diferenças significativas entre as dietas A e $\mathrm{B}$, em que a dieta $\mathrm{B}$ apresentou melhores resultados $(0,77 \pm 0,07)$. A dieta $\mathrm{C}$ não apresentou diferença significativa dos demais tratamentos quanto ao ganho de peso semanal e peso final (Tabela 2).

Os índices de sobrevivência final, conversão alimentar e produtividade final não apresentaram diferença significativa entre os tratamentos. É possível observar que a redução parcial da farinha de peixe e a utilização de ingredientes alternativos na dieta, em sistema de cultivo com bioflocos, não tiveram efeito negativo sobre esses índices zootécnicos. No peso final médio dos camarões, no entanto, a diferença entre as dietas A e B mostra que, ao longo do cultivo, uma alteração nos ingredientes das dietas pode ocasionar perda significativa no ganho de peso dos animais e ter consequências diretas nos custos de produção. Essa diferença pode estar relacionada de modo direto à falta da farinha de peixe na dieta $\mathrm{A}$, a qual perde em qualidade no fornecimento de certos nutrientes essenciais, principalmente ácidos graxos altamente insaturados (HUFA n-3) (Browdy et al., 2006).

A introdução de ingredientes proteicos de origem vegetal foi descrita como fonte de antinutrientes (Ye et al., 2010) que, nesta dieta, existem provavelmente em maior quantidade. A diferença não significativa entre as dietas B e C mostra que uma redução na incorporação de farinha de peixe é possível, sem afetar o ganho de peso final dos animais e os demais parâmetros. Isso corrobora os resultados de Cruz-Suárez et al. (2007), que substituíram a farinha de peixe, em até $80,0 \%$, por ingredientes alternativos (soja e subprodutos avícolas), em dietas comerciais, porém em cultivos semi-intensivos e água clara.

Browdy et al. (2006), substituíram a farinha de peixe da dieta por fontes vegetais orgânicas, tendo utilizado óleo especial de microalgas como fonte dos ácidos graxos essenciais docosahexaenoico (DHA; C22:6n-3) e araquidônico (AA) e apenas $2,0 \%$ de óleo de lula, o que caracteriza uma ração orgânica, sem que esta comprometesse o desempenho dos animais em sistema de bioflocos à densidade moderada (25 camarões $\mathrm{m}^{-2}$ ).

Ray et al. (2010) demonstraram, pela primeira vez, que ouso de dietas com baixos teores de farinha de peixe, em sistema superintensivo em bioflocos sem renovação de água (460 indivíduos $\mathrm{m}^{-3}$ ), pode ser realizado. Isto porque a redução de certos microelementos essenciais (vitaminas e minerais), presentes na farinha de peixe, pode ser suprida também pelos bioflocos (De Schryver et al., 2008).

Os resultados de crescimento, conversão alimentar e sobrevivência na dieta $\mathrm{B}$ mostram que a redução da farinha de peixe nas rações comerciais, substituída por outros ingredientes proteicos em cultivos com bioflocos, é uma possibilidade muito importante para a

Tabela 2. Parâmetros zootécnicos de camarões, cultivados em sistema superintensivo com bioflocos, alimentados com dieta com $0,0 \%(\mathrm{~A}), 12,5 \%$ (B) e $21,0 \%$ de farinha de peixe $(\mathrm{C})^{(1)}$.

\begin{tabular}{|c|c|c|c|c|c|}
\hline Tratamento & Peso médio final & $\begin{array}{l}\text { Ganho de peso semanal } \\
\text { (g) - }\end{array}$ & $\begin{array}{l}\text { Produtividade final } \\
\qquad\left(\mathrm{kg} \mathrm{m}^{-3}\right)\end{array}$ & Conversão alimentar & $\begin{array}{c}\text { Sobrevivência } \\
(\%)\end{array}$ \\
\hline$\overline{\text { Dieta A }}$ & $9,39 \pm 0,31 \mathrm{a}$ & $0,57 \pm 0,03 a$ & $2,41 \pm 0,25 \mathrm{a}$ & $1,68 \pm 0,08 \mathrm{a}$ & $86,20 \pm 0,06 a$ \\
\hline Dieta B & $11,63 \pm 1,38 b$ & $0,77 \pm 0,07 b$ & $2,75 \pm 0,17 \mathrm{a}$ & $1,46 \pm 0,14 a$ & $80,00 \pm 0,04 a$ \\
\hline Dieta C & $10,20 \pm 1,10 \mathrm{ab}$ & $0,64 \pm 0,07 \mathrm{ab}$ & $2,10 \pm 0,19 a$ & $1,56 \pm 0,09 a$ & $73,98 \pm 0,11 \mathrm{a}$ \\
\hline
\end{tabular}

${ }^{(1)}$ Médias seguidas de letras iguais não diferem entre si, pelo teste Tukey, a $5 \%$ de probabilidade. 
redução de custos de produção e redução dos impactos ambientais do cultivo (Amaya et al., 2007; Cruz-Suárez et al., 2007), principalmente se a produção de alimento natural da água for utilizada de forma eficaz (De Schryver et al., 2008; Ray et al., 2010).

Os resultados obtidos no presente trabalho foram promissores, pois a tecnologia em bioflocos é recente no Brasil e, ao mesmo tempo, já apresenta índices de produção bem mais elevados do que no sistema de cultivo semi-intensivo tradicional. A dieta A apresentou produtividade de $2,41 \pm 0,25 \mathrm{~kg} \mathrm{~m}^{-3}$, semelhante à encontrada por Ray et al. (2010), sem a utilização da farinha de peixe na ração. Os camarões peneídeos não sintetizam suficientemente os ácidos graxos altamente insaturados (HUFA n-3) nem os fosfolipídios e esteróis, para satisfazerem as exigências nutricionais mínimas (Cuzon et al., 2004). A redução de fontes oriundas de peixes (farinha e óleo) nas rações diminui também a quantidade de ácidos graxos, minerais traço e outros microelementos essenciais. Para a suplementação desses nutrientes, é importante manter sempre uma quantidade mínima (1-2,0\%) de ingredientes ricos em ácidos graxos (Browdy et al., 2006; Ray et al., 2010).

Os cultivos de camarões devem seguir uma linha cada vez mais ecológica, e é necessário que a indústria aquícola utilize nas dietas ingredientes de menor impacto ambiental, de forma que não afetem o rendimento do cultivo. As melhores taxas de crescimento dos camarões em bioflocos, comparadas com o sistema autotrófico, já foram relatadas em diversos trabalhos (Chamberlain, et al., 2001; Burford et al., 2004; Wasielesky et al., 2006), o que mostra que há suplementação de nutrientes por parte dos microrganismos, além da capacidade de L. vannamei de aproveitar os detritos suspensos na coluna de água (Wasielesky et al., 2006; Avnimelech, 2009). Isto foi comprovado no presente trabalho, em que a dieta B, mesmo tendo apresentado níveis de inclusão de farinha de peixe menores do que os da dieta $\mathrm{C}$, não promoveu diferenças nos índices de crescimento.

Os parâmetros físicos (Tabela 3) e químicos (Tabela 4) da água mantiveram-se nos limites adequados para o crescimento de $L$. vannamei durante todo o experimento. A variação nos níveis de inclusão de farinha de peixes nas dietas de L. vannamei, cultivados em sistema bioflocos, não interferiu na qualidade da água do sistema, a não ser no nível de sólidos sedimentados, em que a dieta sem farinha de peixe apresentou valores maiores. Isto mostra que ingredientes de origem vegetal, sendo menos digestíveis pelos camarões (Cuzon et al., 2004), acabam por se acumular mais na água e por servir de substrato para as bactérias, elevando o nível de sólidos. Os sólidos presentes na água são muito importantes no sistema bioflocos, para a remoção dos compostos nitrogenados que ficam disponíveis em forma de alimento para os animais. Entretanto, o excesso de sólidos na água pode ocasionar entupimento de brânquias e estresse nos

Tabela 3. Parâmetros físicos da água, no cultivo superintensivo de camarões alimentados com dieta com $0,0 \%$ (A), $12,5 \%$ (B) e $21,0 \%$ (C) de farinha de peixe ${ }^{(1)}$.

\begin{tabular}{lcccc}
\hline Tratamento & $\begin{array}{c}\text { Temperatura } \\
\text { manhã }\end{array}$ & $\begin{array}{c}\text { Temperatura } \\
\text { tarde }\end{array}$ & $\begin{array}{c}\text { Sólidos } \\
\text { sedimentados } \\
\left(\mathrm{mg} \mathrm{L}^{-1}\right)\end{array}$ & Turbidez \\
& $-----------\left({ }^{\circ} \mathrm{C}\right)-----------$ & UNT) \\
\hline Dieta A & $28,26 \pm 1,69 \mathrm{a}$ & $29,55 \pm 1,87 \mathrm{a}$ & $29,30 \pm 21,87 \mathrm{a}$ & $188,0 \pm 74,0 \mathrm{a}$ \\
& $(23,60-31,80)$ & $(25,20-34,50)$ & $(6,00-112,50)$ & $(77,0-325,0)$ \\
Dieta B & $28,22 \pm 1,77 \mathrm{a}$ & $29,54 \pm 1,90 \mathrm{a}$ & $25,13 \pm 19,56 \mathrm{~b}$ & $186,0 \pm 83,0 \mathrm{a}$ \\
& $(23,00-31,7)$ & $(25,30-34,50)$ & $(2,50-89,00)$ & $(80,0-376,0)$ \\
Dieta C & $28,36 \pm 1,91 \mathrm{a}$ & $29,67 \pm 1,88 \mathrm{a}$ & $21,90 \pm 16,56 \mathrm{~b}$ & $178,0 \pm 65,4 \mathrm{a}$ \\
& $(24,00-32,30)$ & $(24,90-33,60)$ & $(1,00-100,00)$ & $(46,0-325,0)$ \\
\hline
\end{tabular}

${ }^{(1)}$ Médias seguidas de letras iguais não diferem entre si, pelo teste Tukey, a $5 \%$ de probabilidade. Valores máximos e mínimos entre parênteses.

Tabela 4. Parâmetros químicos da água, no cultivo superintensivo de camarões alimentados com dieta com $0,0 \%$ (A), $12,5 \%$ (B) e $21,0 \%$ (C) de farinha de peixe ${ }^{(1)}$.

\begin{tabular}{|c|c|c|c|c|c|c|c|c|c|}
\hline Tratamento & $\begin{array}{l}\text { Oxigênio dissolvido } \\
\text { manhã }\end{array}$ & $\begin{array}{l}\text { Oxigênio dissolvido } \\
\text { tarde } \\
\left.\mathrm{L}^{-1}\right)\end{array}$ & $\begin{array}{l}\text { Salinidade } \\
\text { (ppt) }\end{array}$ & $\mathrm{pH}$ & ---------------- & -1----------- & $--\left(\mathrm{mg} \mathrm{L}^{-1}\right)$ & Fosfato & Alcalinidade \\
\hline Dieta A & $\begin{array}{l}5,65 \pm 0,74 a \\
(4,10-8,00)\end{array}$ & $\begin{array}{l}5,39 \pm 0,85 \mathrm{a} \\
(3,40-8,00)\end{array}$ & $\begin{array}{l}33,87 \pm 1,09 a \\
(32,1-35,10)\end{array}$ & $\begin{array}{l}7,35 \pm 0,10 \mathrm{a} \\
(7,19-7,54)\end{array}$ & $\begin{array}{l}0,01 \pm 0,02 \mathrm{a} \\
(0,00-0,08)\end{array}$ & $\begin{array}{c}2,21 \pm 4,52 \mathrm{a} \\
(0,07-15,60)\end{array}$ & $\begin{array}{l}41,49 \pm 27,5 \mathrm{ab} \\
(5,84-103,20)\end{array}$ & $\begin{array}{l}4,46 \pm 1,57 a \\
(1,37-7,68)\end{array}$ & $\begin{array}{r}159,00 \pm 19,33 a \\
(128,00-208,00)\end{array}$ \\
\hline Dieta B & $\begin{array}{l}5,53 \pm 0,77 a \\
(3,78-7,80)\end{array}$ & $\begin{array}{l}5,20 \pm 0,92 b \\
(3,03-7,59)\end{array}$ & $\begin{array}{l}33,26 \pm 0,66 a \\
(32,3-34,40)\end{array}$ & $\begin{array}{l}7,38 \pm 0,13 a \\
(7,14-7,65)\end{array}$ & $\begin{array}{l}0,01 \pm 0,02 \mathrm{a} \\
(0,00-0,10)\end{array}$ & $\begin{array}{c}2,03 \pm 3,91 \mathrm{a} \\
(0,04-14,80)\end{array}$ & $\begin{array}{l}51,85 \pm 41,90 a \\
(167,80-4,62)\end{array}$ & $\begin{array}{l}4,38 \pm 1,70 \mathrm{a} \\
(1,42-7,80)\end{array}$ & $\begin{array}{r}154,00 \pm 20,00 \mathrm{a} \\
(120,00-196,00)\end{array}$ \\
\hline Dieta C & $\begin{array}{l}5,68 \pm 0,71 \mathrm{a} \\
(3,55-8,25)\end{array}$ & $\begin{array}{l}5,44 \pm 0,84 \mathrm{a} \\
(3,08-8,10)\end{array}$ & $\begin{array}{c}34,22 \pm 0,77 \mathrm{a} \\
(32,20-35,50)\end{array}$ & $\begin{array}{r}7,38 \pm 0,12 \mathrm{a} \\
(7,19-7,64)\end{array}$ & $\begin{array}{l}0,01 \pm 0,01 \mathrm{a} \\
(0,00-0,04)\end{array}$ & $\begin{array}{c}2,26 \pm 4,35 \mathrm{a} \\
(0,09-17,40)\end{array}$ & $\begin{array}{c}37,35 \pm 20,17 b \\
(6,12-73,80)\end{array}$ & $\begin{array}{l}4,59 \pm 1,76 a \\
(1,63-8,38)\end{array}$ & $\begin{array}{r}157,00 \pm 20,70 \mathrm{a} \\
(114,00-200,00)\end{array}$ \\
\hline
\end{tabular}

${ }^{(1)}$ Médias seguidas de letras iguais não diferem entre si, pelo teste Tukey, a 5\% de probabilidade. Valores máximos e mínimos entre parênteses. 
camarões (Hopkins et al., 1993; Hargreaves, 2006). A turbidez não apresentou diferença significativa entre os tratamentos.

A baixa variação dos parâmetros como oxigênio, amônia e pH mostram a boa estabilidade do sistema bioflocos, em que os sólidos totais se tornam o principal agravante (Hargreaves, 2006).

Os valores de amônia foram baixos em todo o cultivo, não tendo apresentado diferença significativa entre os tratamentos somente entre semanas. O nitrito obteve seu pico máximo na segunda semana de experimento e diminuiu gradativamente e sem apresentar diferença significativa entre os tratamentos. $\mathrm{O}$ nitrato $\left(\mathrm{NO}_{3}-\mathrm{N}\right)$ aumentou gradativamente no decorrer do cultivo e apresentou diferença significativa entre semanas, mas não entre os tratamentos. $\mathrm{O}$ aumento do nitrato no decorrer do experimento já era esperado, tendo-se em vista que o $\mathrm{NO}_{3}$-N é o produto final da nitrificação (Hargreaves, 2006).

$\mathrm{O}$ pH manteve-se entre 7 e 8, adequado para o crescimento do L. vannamei, e não apresentou diferença significativa entre os tratamentos, assim como a alcalinidade e o fosfato.

\section{Conclusão}

É possível a utilização de dietas alternativas no cultivo de camarões Litopenaeus vannamei em sistema bioflocos, reduzindo-se os níveis de farinha de peixe em até 40,0\%, sem comprometer os índices zootécnicos do camarão e a qualidade da água do cultivo.

\section{Agradecimentos}

Ao Conselho Nacional de Desenvolvimento Científico e Tecnológico, por concessão de bolsa; à Financiadora de Estudos e Projetos, à Fundação de Amparo à Pesquisa e Inovação do Estado de Santa Catarina e ao Ministério da Pesca e Aquicultura, pelo apoio financeiro; à Aquatec/Geanerch, pelo fornecimento de larvas de camarões SPF, à Guabi Nutrição Animal pela formulação e fabricação das rações.

\section{Referências}

AMAYA, E.A.; DAVIS, D.A.; ROUSE, D.B. Replacement of fish meal in practical diets for the Pacific white shrimp (Litopenaeus vannamei) reared under pond conditions. Aquaculture, v.262, p.393-401, 2007.
AVNIMELECH, Y. Biofloc technology: a practical guide book. Baton Rouge: World Aquaculture Society, 2009. 182p.

AVNIMELECH, Y. Carbon/nitrogen ratio as a control element in aquaculture systems. Aquaculture, v.176, p.227-235, 1999.

BOYD, C.E.; CLAY, J.W. Evaluation of Belize Aquaculture Ltd.: a superintensive shrimp aquaculture system. Rome: FAO, 2002. $17 \mathrm{p}$.

BROWDY, C.; SEABORN, G.; ATWOOD, H.; DAVIS, D.A.; BULLIS, R.A.; SAMOCHA, T.M.; WIRTH, E.; LEFFLER, J.W. Comparison of pond production efficiency, fatty acid profiles, and contaminants in Litopenaeus vannamei fed organic plant-based and fish-meal-based diets. Journal of the World Aquaculture Society, v.37, p.437-451, 2006.

BURFORD, M.A.; THOMPSON, P.J.; MCINTOSH, R.P.; BAUMAN, R.H.; PEARSON, D.C. The contribution of flocculated material to shrimp (Litopenaeus vannamei) nutrition in a high-intensity, zero-exchange system. Aquaculture, v.232, p.525-537, 2004.

CARRILO, O.; PEDROZA, R. Biodisponibilidad de nutrientes en dietas para camarón. In: ROSAS, C.; CARRILO, O.; WILSON, R.; ANDREATTA, E. (Ed.). Estado actual y perspectivas de la nutrición de los camarones peneidos cultivados em Iberoamérica. México, DF: Cyted, 2006. 322p.

CHAMBERLAIN, G.; AVNIMELECH, Y.; MCINTOSH, R.P.; VELASCO, M. Advantages of aerated microbial reuse systems with balanced C:N. II: Composition and nutritional value of organic detritus. Global Aquaculture Advocate, v.4, p.22-24, 2001.

CLESCERI, L.S.; GREENBERG, A.E.; EATON, A.D. (Ed.). Standard methods for the examination of water and waste water. $20^{\text {th }}$ ed. Washington: American Public Health Association, 1998. 1193p.

CRUZ-SUÁREZ,L.; NIETO-LÓPEZ,M.; GUAJARDO-BARBOSA, C.; TAPIA-SALAZAR, M.; SCHOLZ, U.; RICQUE-MARIE, D. Replacement of fish meal with poultry by-product meal in practical diets for Litopenaeus vannamei, and digestibility of the tested ingredients and diets. Aquaculture v.272, p.466-476, 2007.

CUZON, G.; LAWRENCE, A.; GAXIOLA, G.; ROSAS, C.; GUILLAUME, J. Nutrition of Litopenaeus vannamei reared in tanks or in ponds. Aquaculture, v.235, p.513-551, 2004.

DE SCHRYVER, P.; CRAB, R.; DEFOIRDT, T.; BOON, N.; VERSTRAETE, W. The basics of bio-flocs technology: the added value for aquaculture. Aquaculture, v.277, p.125-137, 2008.

EBELING, J.M.; TIMMONS, M.B.; BISOGNI, J.J. Engineering analysis of the stoichiometry of photoautotrophic, autotrophic, and heterotrophic removal of ammonia-nitrogen in aquaculture systems. Aquaculture, v.257, p.346-358, 2006.

FOOD AND AGRICULTURE ORGANIZATION OF THE UNITED NATIONS. The state of world fisheries and aquaculture, 2008. Rome: FAO, 2009. 195p.

HARDY, R.W. Utilization of plant proteins in fish diets: effects of global demand and supplies of fishmeal. Aquaculture Research, v.41, p.770-776, 2010.

HARGREAVES, J.A. Photosynthetic suspended-growth systems in aquaculture. Aquacultural Engineering, v.34, p.344-363, 2006. 
HOPKINS, J.S.; HAMILTON II, R.D.; SANDIER, P.A.; BROWDY, C.L.; STOKES, A.D. Effect of water exchange rate on the production, water quality, effluent characteristics and nitrogen budgets in intensive shrimp ponds. Journal of the World Aquaculture Society, v.24, p.304-320, 1993.

KUHN, D.D.; BOARDMAN, G.D.; LAWRENCE, A.L.; MARSH, L.; FLICK JUNIOR, G.J. Microbial floc meal as a replacement ingredient for fish meal and soybean protein in shrimp feed. Aquaculture, v.296, p.51-57, 2009.

MCINTOSH, R.P. Changing paradigms in shrimp farming: IV. Low protein feeds and feeding strategies. Global Aquaculture Advocate, v.3, p.44-50, 2000.

NEW, M.B. Responsible aquaculture: is this a special challenge for developing countries? World Aquaculture, v.34, p.26-31, 2003.

OTOSHI, C.A.; TANG, L.R.; MOSS, D.R.; ARCECS, M.; HOLL, C.M.; MOSS, S.M. Performance of Pacific white shrimp, Penaeus (Litopenaeus) vannamei, cultured in biossecure, super-intensive, recirculating aquaculture system. In: BROWDY, C.L.; JORY, D.E. The rising tide - proceedings of the special session on sustainable shrimp farming. Baton Rouge: World Aquaculture Society, 2009. 316p.

RAY, A.J.; LEWIS, B.L.; BROWDY, C.L.; LEFFLER, J.W. Suspended solids removal to improve shrimp (Litopenaeus vannamei) production and an evaluation of a plant-based feed in minimal-exchange, superintensive culture systems. Aquaculture, v.299, p.89-98, 2010.

SAMOCHA, T.M.; DAVIS, D.A.; SAOUD, I.P.; DEBAULT, K. Substitution of fish meal by co-extruded soybean poultry by-product meal in practical diets for the Pacific white shrimp, Litopenaeus vannamei. Aquaculture, v.231, p.197-203, 2004.

SOKAL, R.R.; ROHLF, F.J. Biometry: the principles and practice of statistics in biological research. $3^{\text {rd }}$ ed. New York: W.H. Freeman and Company, 1995. 887p.

STRICKLAND, J.D.H.; PARSONS, T.R. A practical handbook of seawater analysis. $2^{\text {nd }}$ ed. Ottawa: Queen's Printer, 1972. 310p.

TACON, A.G.; METIAN, M. Global overview on the use of fish meal and fish oil in industrially compounded aquafeeds: trends and future prospects. Aquaculture v.285, p.146-158, 2008.

WASIELESKY JUNIOR, W.; ATWOOD, H.; STOKES, A.L.; BROWDY C. Effect of natural production in a zero exchange suspended microbial floc based super-intensive culture system for white shrimp Litopenaeus vannamei. Aquaculture, v.258, p.396-403, 2006.

YE, J.-D.; WANG, K.; LI, F.-D.; SUN, Y.Z.; LIU, X.-H. Incorporation of a mixture of meat and bone meal, poultry by-product meal, blood meal and corn gluten meal as a replacement for fish meal in practical diets of Pacific white shrimp Litopenaeus vannamei at two dietary protein levels. Aquaculture Nutrition, v.17, p.337-347, 2011.

Recebido em 22 de fevereiro de 2011 e aprovado em 23 de agosto de 2011 